\title{
The sensitivity of secondary organic aerosol (SOA) component partitioning to the predictions of component properties - Part 3: Investigation of condensed compounds generated by a near-explicit model of VOC oxidation
}

\author{
M. H. Barley, D. Topping, D. Lowe, S. Utembe, and G. McFiggans \\ Centre for Atmospheric Sciences, School of Earth Atmospheric \& Environmental Sciences, University of Manchester, \\ Manchester, M13 9PL, UK \\ Received: 1 June 2011 - Published in Atmos. Chem. Phys. Discuss.: 27 July 2011 \\ Revised: 24 November 2011 - Accepted: 12 December 2011 - Published: 21 December 2011
}

\begin{abstract}
Calculations of the absorptive partitioning of secondary organic aerosol components were carried out using a number of methods to estimate vapour pressure and nonideality. The sensitivity of predicted condensed component masses, volatility, $\mathrm{O}: \mathrm{C}$ ratio, molar mass and functionality distribution to the choice of estimation methods was investigated in mixtures of around 2700 compounds generated by a near explicit mechanism of atmospheric VOC degradation. The sensitivities in terms of all metrics were comparable to those previously reported (using 10000 semirandomly generated compounds). In addition, the change in predicted aerosol properties and composition with changing VOC emission scenario was investigated showing key dependencies on relative anthropogenic and biogenic contributions. Finally, the contribution of non-ideality to the changing distribution of condensed components was explored in terms of the shift in effective volatility by virtue of component activity coefficients, clearly demonstrating both enhancement and reduction of component masses associated with negative and positive deviations from ideality.
\end{abstract}

\section{Introduction}

Gas to particle mass transfer of semi-volatile components, and the production of secondary organic material (SOA), is an important factor in determining the evolving chemi-

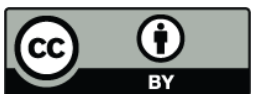

Correspondence to: G. McFiggans (g.mcfiggans@manchester.ac.uk) cal composition of aerosol particles. A representation of the mass transfer, or at least of the equilibrium partitioning between the phases, is necessary for predicting their loading and composition. Even a basic identification of organic compounds in particulate matter is incomplete and a full component mass balance has never been achieved (Hallquist et al., 2009; Hamilton et al., 2008). To attempt prediction of condensable gas phase components, it is possible to make use of mechanistic models that track the oxidation of atmospheric volatile organic compounds (VOCs) all the way through to carbon dioxide and water. Such a mechanism is the Master Chemical Mechanism (MCM) describing the degradation of about 100 VOCs (Jenkin et al., 1997, 2003; Saunders et al., 2003; Bloss et al., 2005).

In Part 1 of this series (McFiggans et al., 2010) the sensitivity of key SOA properties (condensed SOA mass, O:C ratio, molar mass, volatility and functionality distributions) to the choice of vapour pressure $\left(p^{0}\right)$ and non-ideality $\left(\gamma_{i}\right)$ prediction methods used in the partitioning calculations was systematically investigated. The role of SOA complexity in this sensitivity study was also studied by using multiple mixtures of 2,10,100, 1000 or 10000 randomly generated molecules. The results showed that the condensed SOA mass was highly sensitive to the vapour pressure model and much less sensitive to the activity coefficient model and the number of components used to represent the model. In Part 2 of this series (Topping et al., 2011) the methods developed in Part 1 were applied to determine the sensitivity of key SOA particle properties (density, hygroscopicity, and cloud condensation nuclei activation potential) to the models used for $p^{0}$ and $\gamma_{i}$ and the chemical complexity of the SOA. The results

Published by Copernicus Publications on behalf of the European Geosciences Union. 
showed that, providing only water evaporated when drying, predicted hygroscopic growth factors were relatively insensitive to the choice of $p^{0}$ model but more sensitive to the inclusion of non-ideality. If the semi-volatile components were assumed to equilibrate on drying the aerosol particle, the sensitivity massively increased and resulted in calculated hygroscopic growth factors more typical of those measured for common inorganic salts than for atmospheric organic material. In the present paper similar calculations to those developed in Part 1 are done, but instead of using randomly generated compounds the calculations were applied to 2742 atmospherically relevant molecules obtained from the output of the MCM. The sensitivity of the same key SOA properties to $p^{0}$ model and non-ideality were assessed for comparison with the results of Part 1 but with components and concentrations provided by simulations of oxidative degradation of VOCs. No comparisons to the results in Topping et al. (2011) are made (such comparisons may be a topic for further work). In addition the present paper also explores the predicted properties of SOA formed over a wide range of emission scenarios (by varying inputs of anthropogenic and biogenic VOCs and $\mathrm{NO}_{\mathrm{x}}$ ), and the distribution and range of activity coefficients to be found in condensed aerosol.

\section{Methodology}

In McFiggans et al. (2010) sensitivities were calculated using molecular structures based upon randomly combined UNIFAC groups (Fredenslund et al., 1975) subdivided (where appropriate) to provide the groups required for the physical property estimation methods. Atmospheric concentrations were calculated from the number of carbon atoms in a structure after scaling so that the base case model gave $10.0 \mu \mathrm{g} \mathrm{m}^{-3} \mathrm{SOA}$ under standard conditions. These inputs $\left(p^{0}, \gamma_{i}\right.$ (when required), total concentrations of all organic species, temperature and relative humidity) were used in the partitioning model (see Eqs. (1-3) in McFiggans et al., 2010) to determine the condensed mass and composition, from which the other properties, defined above, can be derived. In the present work the input molecular structures are provided by the MCM closed shell oxidation products along with their atmospheric concentrations (changing with scenario).

Vapour pressures $\left(p^{0}\right)$ of all closed-shell (non-radical) compounds formed from VOC degradation by the MCM were predicted using a number of methods. Single timeslices of compound concentrations were extracted from predictions under a range of emission scenarios (described below). Using these as input to the partitioning approach described by Barley et al. (2009) with each of the $p^{0}$ techniques described in McFiggans et al. (2010) (and $\gamma_{i}$ calculated from UNIFAC when exploring non-ideality) the fraction of each component in the condensed phase was calculated, along with the distributions of O:C ratio, molar mass and functional groups.

\subsection{Model scenarios and conditions}

MCM simulations representing a wide range of emission scenarios from UK industrial/urban (high anthropogenic and low biogenic inputs) through to rural background conditions (higher biogenic and low anthropogenic inputs) were conducted. Emissions representing average UK National Atmospheric Emissions Inventory (NAEI) totals for the year 2001 (3740 ktonnes CO, 1130 ktonnes $\mathrm{SO}_{2}, 1680$ ktonnes $\mathrm{NO}_{\mathrm{x}}$, and 1510 ktonnes speciated VOCs with 1330 ktonnes being anthropogenic (AVOCs)) were continuously emitted into the box throughout the base case model run. The snapshots were taken at 18:00 h on the 13th day after the beginning of the simulation.

The detailed anthropogenic emissions used in the box model was based on the NAEI emissions inventory which identifies 650 individual species (Goodwin et al., 2001). In order to allow coupling with the MCM scheme, the speciation was represented by 124 species (made up of alkanes, alkenes/dienes, alkynes, carbonyls, alcohols/glycols, ethers/glycol ethers, acids, esters, aromatics and chlorocarbons - see http://mcm.leeds.ac.uk/MCM/ for a complete list) which accounted for $70 \%$ of NAEI emissions by mass. The outstanding $(\sim 500)$ species, each of which makes a small contribution to the remaining $30 \%$ were emitted as surrogates assigned on the basis of chemical class and reactivity. For example, all longer chain n-alkanes greater or equal to C8 were generally used to represent alkane isomers of same carbon number. Cyclohexane was used to represent all cycloalkanes and duodecane was used to represent all alkanes greater than or equal to C10. This latter lumping assumption means that intermediate volatility organic compounds (iVOCs) emitted in the particulate phase prior to evaporation on dilution, which have been postulated to make a significant contribution to SOA by recondensation after gas phase oxidation (Robinson et al. (2007) and subsequent studies), along with all gaseous components $>\mathrm{C} 12$ are missing from the mechanism. While this omission may not be a problem for ozone production, it is acknowledged that it may have a substantial impact upon SOA formation and may be a source of error in the current study. Similarly biogenic emissions are represented by isoprene, and alpha and beta pinene. It is recognised that this does not take into account the emissions of other more reactive monoterpenes such as limonene or sesquiterpenes such as $\beta$-caryophyllene along with other BVOCs that may be important in UK emissions.

The diurnal profiles are based on the work of Jenkin et al. (2000) where single representative profiles describing seasonal, day-of-week and hour-of-day variations in emissions were assigned to each of over 180 source categories in the NAEI. The model framework is that of a simple box model with no diurnal variation in temperature and boundary layer height. There is obviously no photolysis at night but there is deposition of major inorganic species and other species such as $\mathrm{O}_{3}$. Long lived species were vented based on a boundary 
layer average lifetime of 3 days. This gave a fairly constant diurnal profile in simulated ozone and degradation intermediates after 9 model days; and conditions at 18:00 h represent the late afternoon peak in photochemistry. Similar sensitivities might be reasonably expected from alternative time slices, but this is outside the scope of the present work and could form the subject of further analyses. Further emission scenarios were simulated by independently multiplying the AVOCs, biogenic VOCs (BVOCs) and $\mathrm{NO}_{\mathrm{x}}$ component of the base case emissions by scaling factors of $0.01,0.1$, 10,100 and 1000 to give 216 emission scenarios covering a range of 6 orders of magnitude in the emitted concentrations. To study the trends in predicted aerosol properties and composition with emission levels (see Sect. 3.1 below), the full range of scenarios was used. For the studies on the sensitivity of SOA properties to the $p^{0}$ and $\gamma_{i}$ models used (see Sect. 3.2 below) partitioning calculations were limited to the 27 scenarios in which the scaling factors were restricted to $0.1,1.0$ and 10 to ensure that the more atmospherically relevant scenarios were used. For those calculations using a single scenario, the 1.0/1.0/1.0 $\mathrm{NO}_{\mathrm{x}}$-SF/AVOC-SF/BVOCSF scenario was selected, as it was taken to best represent average UK emissions, and will be referred to as the standard scenario when used in the examples below.

The limitations of such an average UK emissions scenario should be recognised. The complexity of the chemical system lends itself to box model simulations with inherent structural assumptions and simplifications in their input conditions. One of the assumptions introduced in the current study is uniformity of pollutant concentration across each simulation by virtue of the UK averaged emissions, representing the UK boundary layer atmosphere as one well mixed box. Consequently, whilst a wide range of emission scenarios are used in order to investigate a broad range of chemical space relative to the base case scenario of 2001 UK emission totals, no single scenario can be claimed to be completely representative of any real single location.

For each emission scenario the partitioning calculation was conducted at a number of temperature, $\mathrm{RH}$ and involatile core mass values requiring in total 32 sets of calculations for each emission scenario using around 2700 compounds (see Table 1). The temperature and $\mathrm{RH}$ values were selected to cover the range of typical conditions found in a temperate maritime climate such as that of the UK. The core is assumed to interact ideally with all components and is assigned a molar mass of $320 \mathrm{~g} \mathrm{~mole} \mathrm{e}^{-1}$, representing low volatility oxygenated background material, based on the analysis of water soluble organic compounds (WSOC) reported by Reemtsma et al. (2006).

\subsection{The estimation of physical properties using group contribution methods}

The selection of vapour pressure $\left(p^{0}\right)$ estimation methods has already been described by McFiggans et al. (2010) and we
Table 1. Conditions for the partitioning calculations used with each scenario (all combinations used giving 32 cases).

\begin{tabular}{lcc}
\hline Temperature (K) & $\begin{array}{c}\text { Relative Humidity } \\
\%\end{array}$ & $\begin{array}{c}\text { Involatile core } \\
\mu \mathrm{g} \mathrm{m}^{-3}\end{array}$ \\
\hline 273.15 & 10 & 0.5 \\
283.15 & 30 & 3.0 \\
293.15 & 70 & \\
303.15 & 80 & \\
\hline
\end{tabular}

continue to use the same nomenclature in this work. The boiling point $\left(T_{\mathrm{b}}\right)$ estimation methods of Nannoolal et al. (2004); Stein and Brown (1994), and Joback and Reid (1987) will henceforth be referred to as the N, SB and JR methods respectively. The $p^{0}$ equations used in this work are those of Nannoolal et al. (2008) and of Myrdal and Yalkowsky (1997); referred to as the N/VP and MY methods respectively. Hence there are six different methods for estimating $p^{0}$ considered in this work (as in McFiggans et al., 2010 and Topping et al., 2011) of which the N-N/VP method is used as the base case. The other combinations compared to the base case when investigating the sensitivity of SOA properties to $p^{0}$ estimation method are SB-N/VP, JR-N/VP, N-MY, SB-MY, and JR-MY (see Table 2). For more details about the $p^{0}$ estimation methods see McFiggans et al. (2010) and Barley and McFiggans (2010). Parameters for atmospherically important functional groups (e.g. hydroperoxide, peroxyacid, nitrate and PAN) that are not covered by the original methods were either obtained from the literature (e.g. Compernolle et al., 2010; Camredon and Aumont, 2006); or the unknown groups were further divided into smaller groups that were recognised by the estimation method.

Activity coefficients were calculated using original UNIFAC (Fredenslund et al., 1975) with group parameters obtained from Hansen et al. (1991), and using the updated parameters (for $\mathrm{OH}$ and $\mathrm{COOH}$ subgroups) of Peng et al. (2001). More complex groups not covered by UNIFAC were converted into recognised subsidiary groups with the priority being to account for all the heavy atoms (e.g. nitrate $=$ nitro plus ether; carbonate $=$ ester plus ether).

A significant proportion (22\%) of the non-ideal calculations suffered from problems with convergence. These were found to be concentrated at the highest and lowest RH values. For the purpose of this study, all non-ideal calculations which presented convergence problems were excluded. For the standard scenario 7 of the 32 cases failed to converge correctly. There is no indication that these non-converging cases are systematically biased towards either positive or negative deviations from ideality.

For convenience, when calculating the properties of large numbers of component molecules using the relatively complex estimation methods, their fragmentation into 
Table 2. Combinations of $\left(p^{0}\right)$ and $\left(\gamma_{i}\right)$ predictive techniques used within absorptive partitioning calculations.

\begin{tabular}{lllll}
\hline$p^{0 \text { “VP” method }}$ & $p^{0 \text { “Tb” method }}$ & $\left(\gamma_{i}\right)$ method & reference & notes \\
\hline Nannoolal & Nannoolal & ideal $\left(\gamma_{i}=1\right)$ & N-N/VP & "base case” \\
Nannoolal & Stein and Brown & ideal $\left(\gamma_{i}=1\right)$ & SB-N/VP & \\
Nannoolal & Joback & ideal $\left(\gamma_{i}=1\right)$ & JR-N/VP & \\
Myrdal and Yalkowsky & Nannoolal & ideal $\left(\gamma_{i}=1\right)$ & N-MY & \\
Myrdal and Yalkowsky & Stein and Brown & ideal $\left(\gamma_{i}=1\right)$ & SB-MY & \\
Myrdal and Yalkowsky & Joback & ideal $\left(\gamma_{i}=1\right)$ & JR-MY & \\
Nannoolal & Nannoolal & non-ideal $\left(\gamma_{i} \neq 1\right)$ & N-N/VP act & \\
\hline
\end{tabular}

contributing groups was automated. The automated parsing and fragmentation methods are described in more detail (with some examples) in the Supplement. Whilst they can in principle be used with the output of any model, the fragmentation methods used here have been tailored to the output of the MCM.

\subsection{The gas/liquid partitioning model}

The mole based partitioning model has been described in detail elsewhere (e.g. Sect. 2.1 in Barley and McFiggans, 2010; Barley et al., 2009), and yields identical results to the conventional mass based model of Pankow (1994).

The partitioning constant $K_{p, i}$, in units of $\mathrm{m}^{3} \mu \mathrm{mol}^{-1}$ is given by Eq. (1)

$K_{p, i}=\frac{C_{i}^{\mathrm{cond}}}{C_{i}^{\mathrm{vap}} C_{\mathrm{OA}}}=\frac{R T f}{10^{6} \gamma_{i} p_{i}^{0}}$

where $C_{i}^{\mathrm{vap}}$ is the vapour phase molar concentration of component $i, \mu \mathrm{mol} \mathrm{m}^{-3}, C_{i}^{\text {cond }}$ is the condensed phase molar concentration of component $i, \mu \mathrm{mol} \mathrm{m}{ }^{-3}, C_{\mathrm{OA}}$ is the total molar concentration of condensed material, $\mu \mathrm{mol} \mathrm{m}{ }^{-3}, p_{i}^{0}$ is the saturated vapour pressure of component $i$, atm, $R$ is the ideal gas constant $=8.2057 \times 10^{-5} \mathrm{~m}^{3}$ atm mol${ }^{-1} \mathrm{~K}^{-1}, T$ is the temperature, $\mathrm{K} f$ is the fraction of the condensed material that may be considered absorptive, usually considered unity for most absorptive partitioning calculations and $\gamma_{i}$ is the activity coefficient for component $i$ in the liquid phase. Defining a partitioning coefficient $\xi_{i}$ for compound $i$ given its $K_{p, i}$ value:

$\xi_{i}=\left(1+\frac{1}{K_{p, i} C_{\mathrm{OA}}}\right)^{-1}$

where the total molar concentration of condensed material, $C_{\mathrm{OA}}$, is given by the sum of the products of the individual total component concentrations in both phases and their partitioning coefficient:
$C_{\mathrm{OA}}=\sum_{i} C_{i} \xi_{i}$

where $C_{i}=C_{i}^{\mathrm{vap}}+C_{i}^{\mathrm{cond}}$ is the total loading of component $i$, $\mu \mathrm{mol} \mathrm{m}{ }^{-3}$.

As described by McFiggans et al. (2010) the "base case model" for the sensitivity studies is defined as the N-N/VP method with liquid phase ideality; but now using the 2742 MCM compounds (2727 in the special case described below).

\subsection{Special case: hydrolysis of acid anhydrides}

In these simulations, it is assumed that condensation to form aerosol occurs in the moist lower troposphere. Given sufficient time, it might be expected that the complex functionality available to react in the condensed phase would lead to different composition than that predicted assuming attainment of unreactive equilibrium. Owing to the high water vapour mixing ratio and the predicted and measured concentration of water in ambient aerosol, it is probable that some water will lead to hydration of certain hydrophilic molecules and relatively rapid hydrolysis of acid anhydrides. Acids are more polar than anhydrides and are expected to have lower vapour pressures. For example, the conversion of maleic anhydride and methyl maleic anhydride to the corresponding diacids reduce their respective vapour pressures by a factor of about 30000 . Acknowledging that it is only one of many potential classes of condensed reaction in the complex ambient aerosol matrix, all anhydrides were allowed to hydrolyse to the appropriate acid(s) and the vapour pressure of the acids was used to partition these species into the condensed phase: note that this assumption is equivalent to an assumption of instantaneous hydrolysis. In all, 47 acid anhydrides were identified and their hydrolysis led to the loss of 15 compounds from the original list of MCM compounds (from 2742 down to 2727). It should be noted that dicarboxylic acids are a well established, if minor, component of SOA (Bilde et al., 2003; Hallquist et al., 2009), but with the exception of pinic and norpinic acid are absent from the output of the MCM. The MCM does predict significant concentrations of cyclic anhydrides, especially for anthropogenically 
dominated scenarios, and their hydrolysis to the corresponding dicarboxylic acids both increases SOA amounts and provides a higher proportion of carboxylic acid groups in the predicted SOA.

For the estimation of vapour pressures of dicarboxylic acids, a correction for the Nannoolal $T_{\mathrm{b}}$ was included (see Supplement for derivation) to correct a systematic error for this class of compounds.

$\Delta T=-9.2169 C+84.11$

where $C$ is the number of carbon atoms in the diacid. This correction is about $+50 \mathrm{~K}$ for a $\mathrm{C} 4$ diacid, $+20 \mathrm{~K}$ for a $\mathrm{C} 7$ and becomes negative for a $\mathrm{C} 10$ molecule (it is $<2 \mathrm{~K}$ for Pinic acid). It should not be used outside the range $\mathrm{C} 3-\mathrm{C} 12$.

\section{Results and discussion}

\subsection{Dependence of the properties of the condensed material on emission scenario}

Figures 1, S1 and S2 (see Supplement) show predicted particulate properties across a range of emissions. S3 and S4 provide information on the distribution of some key functional groups to help in interpretation. Plots S1 and S2 are analogous to the conventional isopleths used to illustrate the dependence of ozone production on $\mathrm{VOC}$ and $\mathrm{NO}_{\mathrm{x}}$. When plotting ozone isopleths, it is important that the "specific reactivity" of the VOC mixture is constant with increasing VOC. It is not clear that an analogous "specific particulate forming capacity" of a mixture exists that should be maintained constant in the current plots. Figure 1 shows the variability in the properties when simultaneously increasing the AVOC-SF and BVOC-SF at equal rates. Figure S1 in the Supplement shows variability in the properties for the 36 scenarios with the lowest biogenic scaling factor $(0.01)$; $\mathrm{S} 2$ shows them for the 36 scenarios with the lowest anthropogenic input (also $0.01)$. The properties are logarithm of the condensed mass $\left(\mu \mathrm{g} \mathrm{m}^{-3}\right)$; average $\mathrm{O}: \mathrm{C}$ ratio; average molar mass $\left(\mathrm{g} \mathrm{mole}^{-1}\right)$ and average $\mathrm{N}: \mathrm{C}$ ratio. All averages were calculated for the same atmospherically relevant standard condition within a scenario $T=293.15 \mathrm{~K}, \% \mathrm{RH}=70$ and $3.0 \mu \mathrm{g} \mathrm{m}^{-3}$ involatile core using the N-N/VP vapour pressure method and assuming liquid phase ideality. The standard scenario (1.0/1.0/1.0 $\mathrm{NO}_{\mathrm{x}}$-SF/AVOC-SF/BVOC-SF), first introduced in section 2.1 is found at $(0,0)$ in Fig. 1. This scenario is run with 6219 ppt $\mathrm{NO}_{\mathrm{x}}, 28828$ ppt ozone and 31302 ppt VOC, of which $18231 \mathrm{ppt}$ are due to methane. Predicted SOA mass (for the standard condition) is $0.0547 \mu$ gram $\mathrm{m}^{-3}$; average $\mathrm{O}: \mathrm{C}$ ratio is 0.9683 , average $\mathrm{N}: \mathrm{C}$ ratio 0.2112 and average molar mass 219.56 .
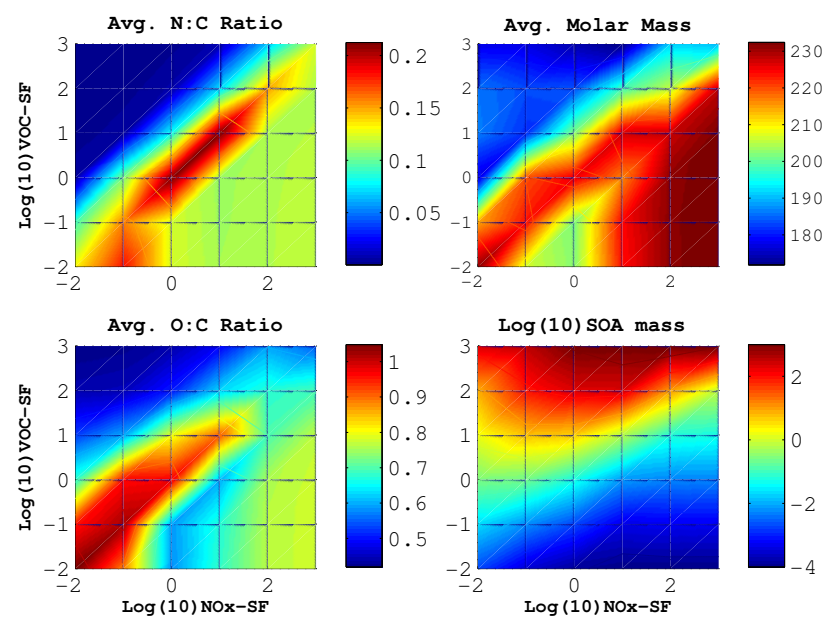

Fig. 1. Surface plots of key properties for those scenarios with AVOC-SF = BVOC-SF; the $\log _{10}$ VOC-SF being plotted on the $y$ axis and $\log _{10} \mathrm{NO}_{\mathrm{x}}-\mathrm{SF}$ along the $\mathrm{x}$ axis in all 4 subplots; all at conditions $T=293.15 \mathrm{~K}, \% \mathrm{RH}=70$ and $3.0 \mu \mathrm{g} \mathrm{m}^{-3}$ involatile core; $p^{0}$ by N-N/VP, $\gamma_{i}=1$. SOA mass is in $\mu \mathrm{g} \mathrm{m}^{-3}$.

The three plots for the amount of SOA mass formed show similar trends with rising $\mathrm{VOC}$ and $\mathrm{NO}_{\mathrm{x}}$, suggesting a minimal dependence on the AVOC-SF:BVOC-SF ratio. Due to the different levels of anthropogenic and biogenic inputs (see Sect. 2.1), and assuming that the NAEI inventory accurately reflects the AVOC:BVOC ratio of emissions; this suggests that biogenic emissions are some 8-9 times more effective in producing SOA than anthropogenic emissions. The other plots reflect more directly the changing chemical composition of the SOA and hence show the effect of individual compounds (or groups of chemically related compounds) that may dominate the SOA composition for a small number of scenarios. The effects of these specific compounds will be added to the overall trends across the range of scenarios and will be different for plots in S1 and S2 (particularly for the $\mathrm{N}: \mathrm{C}$ ratio and molar mass plots due to the relatively small range of values). The combined plot (Fig. 1 where AVOC$\mathrm{SF}=\mathrm{BVOC}-\mathrm{SF}$ ) should make the overall trends clearer by averaging out some of the specific compound effects.

For the SOA mass plots the main differences between S1 and $\mathrm{S} 2$ are the different ratios at which the $\mathrm{NO}_{\mathrm{x}}$ suppression of SOA formation becomes important and that the $\mathrm{NO}_{\mathrm{x}}$ suppression seems to be more effective in the case where the AVOC-SF varies (S1) than when BVOC-SF changes (S2). The suppression of SOA formation by increasing $\mathrm{NO}_{\mathrm{x}}$ has been well documented (see, for example Kroll and Seinfeld, 2008) and reflects whether the alkylperoxy radicals go on to form hydroperoxides or nitrates. In this work we find that SOA mass decreases with increasing $\mathrm{NO}_{\mathrm{x}}$ for constant inputs (constant AVOC-SF or BVOC-SF) except at high VOC and relatively low $\mathrm{NO}_{\mathrm{x}}$ levels where there is increasing SOA formation up to a peak. This is observed for AVOC-SF of 1 or greater $(\mathrm{S} 1$ : BVOC-SF $=0.01)$ and BVOC-SF of 100 
or greater $(\mathrm{S} 2: \mathrm{AVOC}-\mathrm{SF}=0.01)$. For $\mathrm{S} 1$ the peak occurs at a AVOC-SF: $\mathrm{NO}_{\mathrm{x}}-\mathrm{SF}$ ratio of 10:1, and for $\mathrm{S} 2$ the peak is at BVOC-SF: $\mathrm{NO}_{\mathrm{x}}-\mathrm{SF}$ ratio of about 100:1. The line of this peak roughly corresponds to the loss of hydroperoxide groups from the SOA (see Fig. S3 and S4 top left hand plot). If these ratios (10:1 and 100:1) are converted back to the inputs then the anthropogenic peak is at an AVOC: $\mathrm{NO}_{\mathrm{x}}$ ratio of about 8:1 and the biogenic peak is at a BVOC: $\mathrm{NO}_{\mathrm{x}}$ ratio of about 11:1. Hence the AVOC: $\mathrm{NO}_{\mathrm{x}}$ ratio for this work is in good agreement with the ratio of 10:1 reported for the degradation of 1-octene (Camredon et al., 2007), though rather higher than the ratios (1.5:1 to 4:1) reported for the oxidation of a mixture of 4 anthropogenic VOCs (Vivanco et al., 2011). The BVOC: $\mathrm{NO}_{\mathrm{x}}$ ratio of $11: 1$ is in good agreement with the $10-20 \mathrm{ppbC} \mathrm{ppb}^{-1} \mathrm{NO}_{\mathrm{x}}$ for $\beta$-pinene found by Pandis et al. (1991), and consistent with the high yields reported by Dommen et al. (2006) for isoprene: $\mathrm{NO}_{\mathrm{x}}$ ratios of 10.5:1 to 7:1 although other authors report maximum yields at BVOC: $\mathrm{NO}_{\mathrm{x}}$ ratios closer to 1:1 for both isoprene (Kroll et al., 2006; Chan et al., 2010) and $\alpha$-pinene (Capouet et al., 2008). However it has been noted that the different oxidant conditions used in these studies may affect the fate of the $\mathrm{RO}_{2}$ radical and impact upon the BVOC: $\mathrm{NO}_{\mathrm{x}}$ ratio for maximum SOA formation (Hoyle et al., 2011).

The amount of SOA formed with increasing $\mathrm{VOC} / \mathrm{NO}_{\mathrm{x}} \mathrm{ra}-$ tio at constant $\mathrm{NO}_{\mathrm{x}}-\mathrm{SF}(=0.1)$ was investigated. In Fig. S1 a factor of 10 increase in AVOC-SF causes a roughly similar increase in SOA formed. For the case where the biogenic input is increased (Fig. S2) the amount of SOA formed initially increases much faster (up to 100 times for a 10 fold increase in BVOC-SF) but then tails off until at the highest levels changing the BVOC-SF from 100 to 1000 only leads to double the mass of SOA formed. These results are similar to those reported by Capouet et al. (2008) but a detailed mechanistic investigation is outside the scope of the current paper, but should form the focus of a more comprehensive study.

For the $\mathrm{N}: \mathrm{C}$ ratio it would be expected that at high VOC, low $\mathrm{NO}_{\mathrm{x}}$, where a lot of SOA is formed then the $\mathrm{N}: \mathrm{C}$ ratio would be very low and this is seen in both Figs. S1 and S2. On moving towards high $\mathrm{NO}_{\mathrm{x}}$ the amount of SOA drops and the $\mathrm{N}: \mathrm{C}$ ratio increases but the shape of this change is determined by the distribution of nitro and nitrate groups (see Figs. S3 and S4). For the low AVOC case (Figs. S2, S4) nitro groups are limited to a small region at very low $\mathrm{NO}_{\mathrm{x}}$ and very low BVOC but nitrates make a significant contribution across a wide range of $\mathrm{NO}_{\mathrm{x}}$ values giving the plateau feature seen in Fig. S2 with no maximum. In Fig. S1 nitrates are more restricted to high $\mathrm{NO}_{\mathrm{x}}$ values (Fig. S3) and the $\mathrm{N}: \mathrm{C}$ ratio at lower $\mathrm{NO}_{\mathrm{x}}$ are dominated by nitro groups. These nitro groups are associated with a limited number of compound types (for example, a series of multifunctionalized peroxybridged cyclohexene compounds with very low predicted vapour pressures) which dominate anthropogenic SOA composition across a range of scenarios and give the distinctive ridge feature (and maximum in $\mathrm{N}: \mathrm{C}$ ratio) seen in $\mathrm{S} 1$. PAN groups make a small contribution to the $\mathrm{N}: \mathrm{C}$ ratio for anthropogenic SOA (Fig. S3). Figure 1 is an average of the plots in Figs. S1 and S2 so the ridge and maximum in $\mathrm{N}: \mathrm{C}$ ratio are visible in this figure as well.

The molar mass plots in Figs. S1 and S2 show the expected broad trends: regions with large amounts of SOA give the lowest molar mass (as more volatile, lower molar mass material is included in the condensation process) and conversely the regions with the smallest amounts of SOA tend to have the highest molar masses. This is most clearly seen in S2; in S1 (the low BVOC case) the effects of specific compounds are added to the overall trends. For example the pale blue region at $\log \left(\mathrm{NO}_{\mathrm{x}}-\mathrm{SF}\right)=0, \log (\mathrm{AVOC}-\mathrm{SF})=-2$ to 0 is due to the large contribution to SOA of an alkene substituted with a nitro, aldehyde and acid group (molar mass $=159$ ) in contrast to the red region immediately to the left which is dominated by the peroxybridged cyclohexenes mentioned above (molar mass $=$ up to 290). The substituted alkene also makes a strong contribution to the maximum seen in the $\mathrm{N}: \mathrm{C}$ plot mentioned above.

In the O:C ratio plots in Figs. S1 and S2 regions of high SOA mass (low $\mathrm{NO}_{\mathrm{x}}$ /high VOC) show reduced O:C ratio due to the extra condensing material being more volatile, this being associated with fewer oxygenated functional groups. The pattern in the rest of the plot is not very clear (particularly in Fig. S1) and this is due to the effect of specific compounds. In Fig. $\mathrm{S} 1$ the pronounced ridge and maximum in $\mathrm{O}: \mathrm{C}$ ratio occurs in the same region to the similar feature in the $\mathrm{N}: \mathrm{C}$ ratio plot and will be due to the high O:C ratios of the peroxybridged cyclohexenes $(\mathrm{O}: \mathrm{C}$ ratio $=1.7-2.0)$ and substituted alkene $(\mathrm{O}: \mathrm{C}$ ratio $=1.0)$ which dominate the SOA composition in this region. In Fig. S2 there is a weak ridge structure with a maximum at very low VOC/very low $\mathrm{NO}_{\mathrm{x}}$. This is associated with SOA being dominated by $\mathrm{C} 5$ diols with ketone and hydroperoxide groups $(\mathrm{O}: \mathrm{C}$ ratio $=1.0-1.2)$. At higher $\mathrm{NO}_{\mathrm{x}}$ ratios polyfunctional nitrates with $\mathrm{O}: \mathrm{C}$ ratios of about $0.7-0.9$ become important contributors to SOA. Figure 1 is an average of the plots in Figs. S1 and S2 so the ridge and maximum in O:C ratio are visible in this figure as well. Significant differences are also seen in the high $\mathrm{NO}_{\mathrm{x}} /$ low VOC region. For the low AVOC case (Fig. S2) the SOA composition in this region is dominated by three compounds: a polyfunctional nitrate with an $\mathrm{O}: \mathrm{C}$ ratio of 0.875 ; a cyclobutane derivative with a carboxylic acid and PAN group (O:C ratio $=0.875-$ note increase in PAN at high $\mathrm{NO}_{\mathrm{x}}$ in Fig. S4); and a cyclobutane derivative bearing carboxylic acid and nitrate groups $(\mathrm{O}: \mathrm{C}$ ratio $=0.625)$. At low $\mathrm{VOC}$ and between a $\mathrm{NO}_{\mathrm{x}}{ }^{-}$ $\mathrm{SF}$ value of 10 and 1000 the composition does not change much resulting in the large area in this plot with O:C ratio of about $0.7-0.8$. The behaviour of the plot for low BVOC case is more complex and a detailed description of the limiting behaviour in this region is outside the scope of this work. 


\subsection{Sensitivity of SOA properties to estimated vapour pressures and activity coefficients}

\subsubsection{Sensitivity of SOA mass}

Figure 2 shows the sensitivity of condensed SOA mass to the methods used to estimate vapour pressure and the treatment of solution ideality across all conditions for 27 model scenarios (all combinations of scaling factors $0.1,1.0$ and 10). The base case uses the $p^{0}$ method N-N/VP with all $\gamma_{i}$ set to unity (ideal case). In the first five boxes of Fig. 2 the liquid phase is assumed to be ideal but the $p^{0}$ method is changed and the factor by which the condensed mass changes is plotted. In the sixth box the $p^{0}$ method is N-N/VP, liquid phase ideality is still assumed but all the acid anhydrides are hydrolysed. In the seventh box the vapour pressure used is still N-N/VP but the $\gamma_{i}$ of all components are calculated by UNIFAC. Comparison of the first six bars with the final bar demonstrates that the condensed mass can change by several orders of magnitude for some cases with a change in $p^{0}$ estimation method but the effect of including non-ideality is much less significant (very few cases show a mass less than a tenth of the base case). These results confirm the significant conclusions drawn from Figs. 3 and 4 in McFiggans et al. (2010) and are similarly in contrast with the finding that non-ideality is a greater contributor to the variability in particle hygroscopicity as shown by Topping et al. (2011). The box-whisker plot for N-N/VP act in Fig. 2 shows that the inclusion of non-ideality can both increase and decrease SOA mass compared to the ideal base case. The results presented in Compernolle et al. (2009) show that the effect on yield of including non-ideality in the partitioning calculation can result in increased SOA mass under dry conditions but with the inclusion of water, and particularly at high \% RH, the amount of SOA is reduced compared with the ideal calculations (see their Fig. 3). A plot of the ratio of SOA Mass(Non-Ideal) to SOA Mass(Ideal) (inversely related to the average effective activity coefficient) against $\% \mathrm{RH}$ for the scenarios used in Fig. 2 is shown in Fig. S5 in the Supplement. The lack of a consistent trend with \% RH shows that neither the direction nor magnitude of non-ideality can be predicted based only on how moist the atmosphere is. The dataset shown in Fig. S5 is incomplete due to those cases (concentrated among the $10 \%$ and $80 \%$ RH data) where the non-ideal calculation failed to converge (see Sect. 2.2). Given this caveat the following tentative conclusions can be drawn from Fig. S5. At each temperature you are roughly equally likely to get more mass than less mass along with increasing scatter with rising $\% \mathrm{RH}$ at all temperatures other than $273 \mathrm{~K}$. The scatter at higher $\% \mathrm{RH}$ increases with increasing temperature; and there seems to be little core mass dependence (i.e. little dependence on the total condensed mass; given that total condensed mass increases with core mass).

The plots are also consistent with the conclusions about the vapour pressure estimation methods reported in Barley

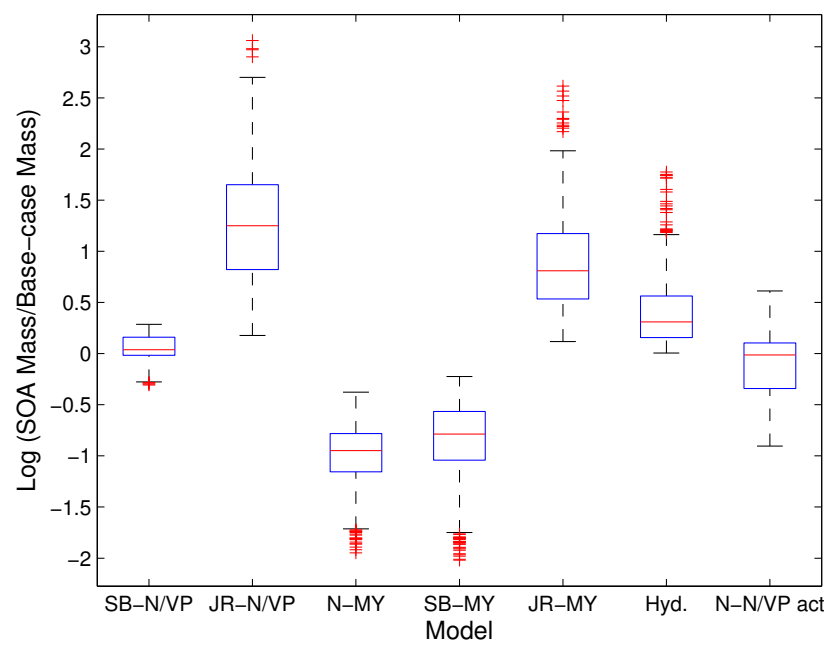

Fig. 2. Box-whisker plots showing the sensitivities of the predicted SOA mass, compared to the base case, across all cases for 27 scenarios using the partitioning model with (a) five vapour pressure estimation methods (plots 1-5, 2742 compounds, $\gamma_{i}=1$ ); (b) plot 6 shows the effect of hydrolysis of acid anhydrides (2727 MCM compounds, $p^{0}$ by N-N/VP, $\gamma_{i}=1$ ); (c) plot 7 shows the sensitivity to non-ideality ( 2742 compounds, $p^{0}$ by N-N/VP, $\gamma_{i}$ by UNIFAC).

and McFiggans (2010): the SB and $\mathrm{N}$ methods for $T_{\mathrm{b}}$ estimation give similar results while the JR method significantly overestimated $T_{\mathrm{b}}$. Hence in Fig. 2 the SB-N/VP method shows the smallest interquartile range (size of the box in the box-whisker plot) of any of the vapour pressure methods while the two Joback methods (JR-N/VP and JR-MY) show a significant bias towards increased mass. Similar results have been reported by Valorso et al. (2011) where the JR-MY method consistently predicted more SOA than the N-N/VP method although the differences were much smaller than those shown in Fig. 2. The difference in sensitivity can be explained by the larger SOA mass reported by Valorso et al. (2011). The vapour pressure values predicted by the various models tend to converge as compounds become more volatile; so with increased SOA mass, more volatile components become included in the SOA and the sensitivity to the vapour pressure model is reduced.

Also, the methods using the MY vapour pressure method generate less SOA mass than the corresponding methods using the N/VP method (in some cases by some orders of magnitude) and this has been explained by the MY vapour pressure equation underestimating the slope of the vapour pressure curve (Barley and McFiggans, 2010). Compernolle et al. (2010) also noted the large differences in estimated vapour pressures when using the MY and the N/VP vapour pressure equations, finding that the N-MY method under predicted their experimental SOA amounts while the N-N/VP method gave much better results.

Some statistics for the scatter depicted in this figure are summarised in Table 3 and confirm that the non-ideal model 
shows less deviation from the base case than all the $p^{0}$ models except SB-N/VP. Note that the hydrolysis of anhydrides can substantially increase the amount of SOA mass (several cases show an increase of between 10 and 100 times) and this is associated with a combination of high levels of $\mathrm{NO}_{\mathrm{x}}$ and AVOC combined with low levels of BVOC, so it may be expected that some of the measured dicarboxylic acids in the ambient atmosphere under moist polluted conditions may be attributable to the hydrolysis of anhydrides.

\subsubsection{SOA composition}

Here we briefly assess the impact of the predictive technique on the SOA composition; specifically the order of compound contribution to SOA. The chemical composition of the SOA is very sensitive to the vapour pressure model used and the inclusion of non-ideality. In Fig. 3 this is shown by the change in position of the top 200 compounds with respect to the order using the base case method at $293 \mathrm{~K}$ and $70 \% \mathrm{RH}$ for the standard scenario. The methodology is taken from Valorso et al. (2011) where the authors describe SOA formation using a much more detailed oxidation mechanism than the MCM (GECKO-A see Aumont et al., 2005; Camredon et al., $2007)$ but degrading only one VOC ( $\alpha$-pinene) and demonstrate the change in SOA composition with vapour pressure model using similar figures. Figure 3 confirms that all the models, except the special case involving hydrolysis of acid anhydrides, cause a substantial reordering of the compounds. For a compound to appear in Fig. 3 it must be in the top 200 compounds for both the base case and the model used to test the sensitivity of SOA. The number of compounds that satisfy this requirement provide a metric for the degree of reordering of the compounds (high value minimal reordering; low value more reordering). Hence for Fig. 3 the degree of reordering increases in the order:- Hyd 189, SB-N/VP 180, N-MY 168, SB-MY 164, and JR-MY 160, JR-N/VP 147 and $\mathrm{N}-\mathrm{N} / \mathrm{VP}$ act 126 . The change in the JR-N/VP parameter with SOA mass was also investigated and was found to vary between 146 at the lowest SOA mass up to 164 at the highest masses, suggesting that at higher SOA masses there is less reordering of compounds with a change in vapour pressure model. This may explain why the degree of scatter seen in Fig. 3 (SOA mass $=0.0547 \mu \mathrm{g} \mathrm{m}^{-3}$ by N-N/VP) is much greater than that seen in Fig. 7 of Valorso et al. (2011) (SOA mass $>60 \mu \mathrm{g} \mathrm{m}^{-3}$ ).

Figure S6 in the Supplement shows similar results for both a low temperature/high \% RH case, and a high temperature/low \% RH case using the standard scenario confirming that the results seen in Fig. 3 are typical. The contribution of the top 200 compounds to the SOA is $>99$ mole \% for all the models considered. The distribution of the SOA species is very uneven so the top 2 compounds typically contribute $20-45 \%$ and the top 10 compounds some $50-75 \%$. The model including the hydrolysis of acid anhydrides is exceptional in that the predicted SOA is dominated by two
Table 3. Some statistics for the variation in factor difference in SOA mass with $\left(p^{0}\right)$ and $\left(\gamma_{i}\right)$ models compared to the base case see Fig. 2.

\begin{tabular}{lrrrr}
\hline Model & Median & Mean & Std. Dev. $(\sigma)$ & RSD $=\sigma /$ Mean \\
\hline SB-N/VP & 1.09 & 1.19 & 0.31 & 0.26 \\
JR-N/VP & 17.78 & 39.87 & 82.46 & 2.07 \\
N-MY & 0.11 & 0.13 & 0.08 & 0.63 \\
SB-MY & 0.16 & 0.19 & 0.13 & 0.69 \\
JR-MY & 6.45 & 14.89 & 31.80 & 2.14 \\
Hyd & 2.04 & 3.68 & 5.74 & 1.56 \\
N-N/VP act & 0.97 & 0.97 & 0.62 & 0.63 \\
\hline
\end{tabular}

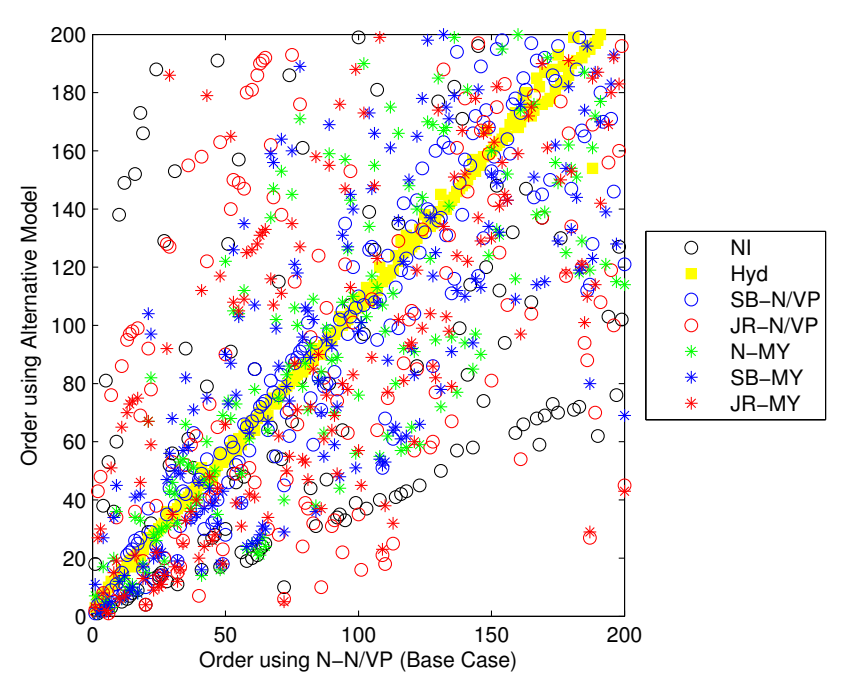

Fig. 3. Scatter plots showing the changes in the order of the top 200 compounds contributing to predicted SOA mass, compared to the base case (x-axis). SOA compositions used were from the standard (1.0/1.0/1.0) scenario; with $T=293.15 \mathrm{~K}, \% \mathrm{RH}=70$ and $3.0 \mu \mathrm{g} \mathrm{m}^{-3}$ involatile core. $\mathrm{NI}=\mathrm{N}-\mathrm{N} / \mathrm{VP}$ act.

compounds (maleic acid and methylmaleic acid) which contribute 77.8 mole $\%$ to the SOA; the next 8 components contribute $10.9 \%$. Hence the predicted SOA composition is dominated by a small number of compounds with a long tail of compounds that make a vanishingly small contribution to the aerosol.

It is not surprising that hydrolysis of anhydrides does not greatly change the compound ordering as the majority of compounds have the same vapour pressure as they have in the base case calculation. The top two compounds in the hydrolysed SOA do not appear in Fig. 3 because the corresponding anhydrides are too volatile to be in the top $200 \mathrm{com}$ pounds for the base case SOA. The hydrolysis of anhydrides changes the vapour pressure of some 32 compounds (out of 2727) and substantially increases the SOA mass which does affect the relative contributions of the other components but the effect is small compared with the effects upon the order 
due to changing the $p^{0}$ or $\gamma_{i}$ models. Potentially of greatest interest is that the largest re-ordering of the most important contributing compounds results from the inclusion of non-ideality. Given the relatively low variation in mass attributable to the inclusion of non-ideality, it is evident that the reordering must be the result of simultaneous positive and negative deviations from ideality in the multicomponent mixture. This was confirmed by an analysis of how the representation of specific functional groups in the SOA changed with the inclusion of non-ideality. For the standard conditions (which includes $70 \% \mathrm{RH}$ ), the change from an ideal to a non-ideal calculation resulted in carboxylic acids on average moving up by 99 places, monoalcohols by 136 places and bis-phenols by 214 places. In contrast nitrates moved down by 202 places, mononitro compounds by 74 places and PANs by 308 places. This reordering clearly reflects the effects of negative deviations from ideality for the first set of functionalities in aqueous solution; and positive deviations from ideality for the second set of functional groups. Figure S6 in the Supplement shows that the reordering of compounds due to the inclusion of non-ideality is further exaggerated under cooler, moister conditions and only slightly less important under warm dry conditions. For SOA mixtures formed at medium or high \% RH the water-organic interactions will be more important than the organic-organic interactions. The more extensive reordering of compounds under cooler, moister conditions, is consistent with the movement of the SOA component activity coefficients away from unity. From studies on the vapour-liquid equilibria of binary mixtures (including systems containing water) it is generally observed that solute deviations from ideality (whether negative or positive) tend to get larger, both at lower temperatures (Gmehling, 2009), and at higher dilutions (Gmehling et al., 2002).

\subsubsection{Volatility distributions}

Figure 4 shows the volatility distribution of the $2742 \mathrm{MCM}$ compounds using the standard scenario (1.0/1.0/1.0 for $\mathrm{NO}_{\mathrm{x}}{ }^{-}$ SF/AVOC-SF/BVOC-SF) at atmospherically relevant conditions $\left(T=293.15 \mathrm{~K}, \% \mathrm{RH}=70\right.$, core $\left.=3.0 \mu \mathrm{g} \mathrm{m}^{-3}\right)$. This case was selected simply for illustration, representing simulations under average UK emission conditions with temperature and $\mathrm{RH}$ selected to represent conditions in the lower Troposphere, while ensuring that the appropriate non-ideal calculations converged correctly. It should be noted that under these conditions, the amount of SOA predicted (about $0.055 \mu \mathrm{g} \mathrm{m}^{-3}$ for the base case) is substantially below both the $10 \mu \mathrm{g} \mathrm{m}^{-3}$ condensed mass loading used as the reference case in McFiggans et al. (2010); and the amount of SOA typically found in the lower Troposphere. For example reported SOA amounts found during the TORCH campaign ranged from 0.92 to $5.91 \mathrm{\mu g} \mathrm{m}^{-3}$ (Johnson et al., 2006); while Heald et al. (2005) reported average organic carbon aerosol concentrations of $4 \mu \mathrm{g} \mathrm{m}^{-3}$ during the ACE-Asia study.
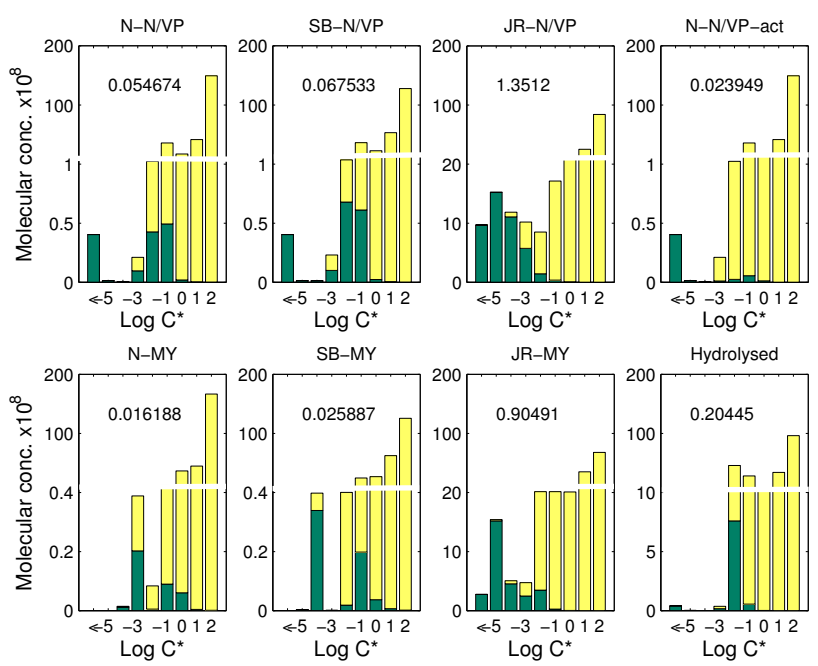

Fig. 4. Predicted binned component volatility for $2742 \mathrm{MCM}$ compounds (except panel 8: 2727 compounds) with concentrations taken from the standard scenario (1.0/1.0/1.0 $\mathrm{NO}_{\mathrm{x}^{-}}$ SF/AVOC-SF/BVOC-SF) with $T=293.15 \mathrm{~K}, \% \mathrm{RH}=70$ and $3.0 \mu \mathrm{g} \mathrm{m}^{-3}$ involatile core. The abscissa is the base 10 logarithm of the saturation concentration of the components in the respective volatility bin, while the y-axis gives the cumulative molecular concentration (in molecules $\mathrm{cm}^{-3}$ ) for each bin: please note scale change half way up the $y$-axis in each panel. The green bars correspond to the particulate and the yellow to the vapour phase. The total condensed SOA mass (in $\mu \mathrm{g} \mathrm{m}^{-3}$ ) is indicated on each panel.

The components are binned according to their $C_{i}^{*}$ value where this parameter is the inverse of $K_{p, i}$ as defined by Eq. (1) in McFiggans et al. (2010). As found in this earlier paper, the volatility distributions show substantial sensitivity to the vapour pressure model used with components moving between the $\log C_{i}^{*}$ bins. The tendency for the JR method to overestimate $T_{\mathrm{b}}$, leading to reduced vapour pressures, causes the bunching of compounds into the lower volatility bins $\left(\log C_{i}^{*}<-2\right)$. If the hydrolysed case is compared to the base case then it is clear that the hydrolysis process reduces the concentration in bin $\log C_{i}^{*}=+2$ and possibly some further bins of even higher volatility, while significantly increasing the amount of material in $\operatorname{bin} \log C_{i}^{*}=-2$. This is due to the hydrolysis of some highly abundant cyclic anhydrides to give much less volatile dicarboxylic acids which then appear in the $\log C_{i}^{*}=-2$ bin. The effect of the inclusion of non-ideality in the partitioning calculation changes the volatility distribution much less than the two $T_{\mathrm{b}}$ by JR $p^{0}$ methods, but by more than some of the other methods (note that $\log C_{i}^{*}$ values for the non-ideal case do not include the activity coefficients and represent the saturation concentrations of the components under ideal conditions). In general these figures show that the assignment of compounds to a volatility bin is extremely sensitive to the $p^{0}$ and $\gamma_{i}$ models used. Hence the least volatile compounds (a series of multifunctionalised peroxybridged cyclohexenes mentioned 
in Sect. 3.1) as determined by the N-N/VP method are in bin $C_{i}^{*}<-5$ using this method, as they are for the SB-N/VP, hydrolysed, and non-ideal models. For the N-MY model they appear in the $\log C_{i}^{*}=-3$ bin and for the SB-MY model they are in the $\log C_{i}^{*}=-4$ bin. Given this sensitivity to the $p^{0}$ model the idea that lumping species together by assigning molecules to volatility bins on the basis of vapour pressure and being able to make meaningful predictions of their properties seems highly optimistic.

\subsubsection{O:C ratio and molar mass distributions}

The two panels in Fig. 5 show the concentration of the condensed compounds binned according to their molar mass and $\mathrm{O}: \mathrm{C}$ ratio for two vapour pressure models (N-N/VP (base case) and JR-N/VP) corresponding to the first and third panels on the top row of Fig. 4 for the "standard" 1.0/1.0/1.0 emission scenario under the same conditions as Fig. 4. The colour axis is the base 10 logarithm of the cumulative concentration in the respective bin, with the bin size being defined as 0.25 units of O:C ratio by $20 \mathrm{amu}$. As expected, more condensed material is predicted when the JR estimation method is used for $T_{\mathrm{b}}$. For both plots the most abundant condensed molecules have a molar mass in the range 150220 and an $\mathrm{O}: \mathrm{C}$ ratio of 0.5 to 1.0. Figure 6 shows the ratio of the binned condensed phase loading using the two vapour pressure methods. If the extra condensing mass had the same properties (in this case molar mass and $\mathrm{O}: \mathrm{C}$ ratio) as the material predicted to condense using the base case then Fig. 6 would be a uniform colour (constant factor across all bins). The fact that it is not uniform shows that changing the vapour pressure method creates a bias in the other properties of the SOA: in this case the molar mass and O:C ratio averaged over all the SOA move to lower values.

Comparing the position of the concentration peaks in Figs. 5 and 6 (despite the broadness of the features) it is clear that the peak in Fig. 6 is at a substantially lower molar mass than the peaks in Fig. 5. This clearly demonstrates that the extra material condensing when using the JR-N/VP $p^{0}$ model has, on average, a lower molar mass than the material condensing using the N-N/VP model. Although it is difficult to see in these figures, close examination of Fig. 6 shows that the main peak is at an $\mathrm{O}: \mathrm{C}$ ratio of about 0.45 while the peaks in Fig. 5a, b are mainly at $\mathrm{O}: \mathrm{C}$ ratio 0.5 . The additional material predicted to condense when using the JRN/VP model has a slightly lower O:C ratio consistent with less functionalized molecules contributing to the condensed material. This confirms (as stated in McFiggans et al., 2010) that the choice of estimation methods used in absorptive partitioning calculations will substantially impact upon the selection of semivolatile components and hence the properties (such as $\mathrm{O}: \mathrm{C}$ ratio and average molar mass) of the organic fraction of the condensed phase.

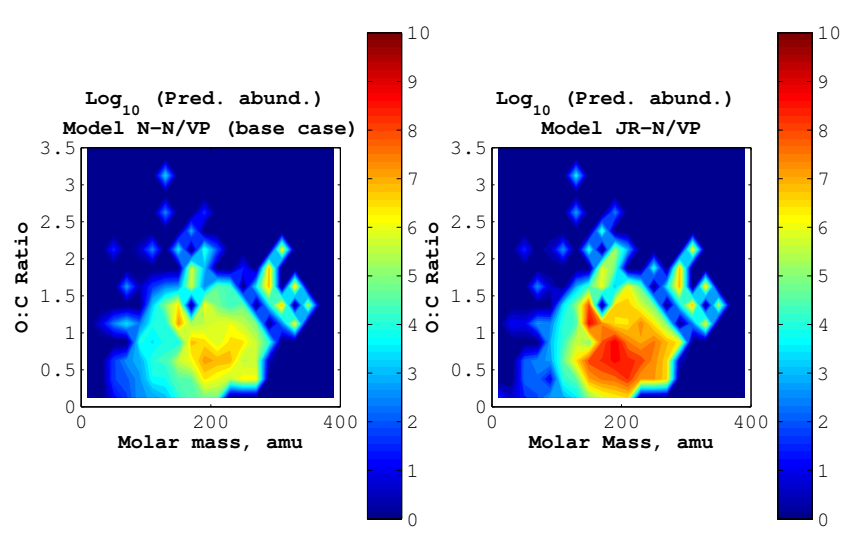

Fig. 5. Predicted binned organic component condensed moles plotted as a function of molar mass and O:C ratio for the $2742 \mathrm{MCM}$ compounds with concentrations taken from the standard scenario (1.0/1.0/1.0 NO $\left.\mathrm{NO}_{\mathrm{x}}-\mathrm{SF} / \mathrm{AVOC}-\mathrm{SF} / \mathrm{BVOC}-\mathrm{SF}\right)$ with $T=293.15 \mathrm{~K}$, $\% \mathrm{RH}=70$ and $3.0 \mu \mathrm{g} \mathrm{m}^{-3}$ involatile core. The colour axis is the base 10 logarithm of the cumulative concentration of the condensed components (in molecules $\mathrm{cm}^{-3}$ ) in the respective bin. The bins are defined by a subdivision of the O:C scale into bin width of 0.25 , and the MW scale into bin widths of $20 \mathrm{~g} \mathrm{~mole}^{-1}$. The left hand panel shows the distribution for the predicted composition generated using the N-N/VP (base case) model while the right hand panel shows a similar plot for the JR-N/VP model ( $\gamma_{i}=1$ for both panels).

Figure 7 shows the difference and variability in the average O:C ratio and molar masses of the predicted condensed SOA with different models across 27 scenarios (all combinations of scaling factors $0.1,1.0$ and 10). The black asterisk (and associated black box-whisker plot) shows the median $\mathrm{O}: \mathrm{C}$ ratio and molar mass for the base case; the black triangle shows these parameters for the non-ideal case; and the black circle shows these parameters for the case with hydrolysis. The remaining coloured symbols are associated with the box-whisker plots and show the variation of these parameters with vapour pressure method. The differences in the median values between the base case and the hydrolysed case result from the maleic acid derivatives in the hydrolysed case as these have lower molar mass and higher $\mathrm{O}: \mathrm{C}$ ratio than the average of the condensed components. It is clear from the box-whisker plots that the spread in $\mathrm{O}: \mathrm{C}$ ratio and molar mass values is much smaller for the two methods that use $T_{\mathrm{b}}$ by JR. The increase in condensed mass associated with this boiling point method also leads to a lower median $\mathrm{O}: \mathrm{C}$ ratio and molar mass-consistent with higher volatility components with a lower $\mathrm{O}: \mathrm{C}$ ratio and lower molar mass becoming included in the SOA mass.

This plot can be compared to Fig. 10 in McFiggans et al. (2010). In Fig. 7 the median values of both O:C ratio and molar mass are clearly lower for the methods using the JR $T_{\mathbf{b}}$ estimation methods. In Fig. 10 of the earlier paper the corresponding difference is less clear although the JR-N/VP does come out with the lowest O:C ratio. In Fig. 7 the median 


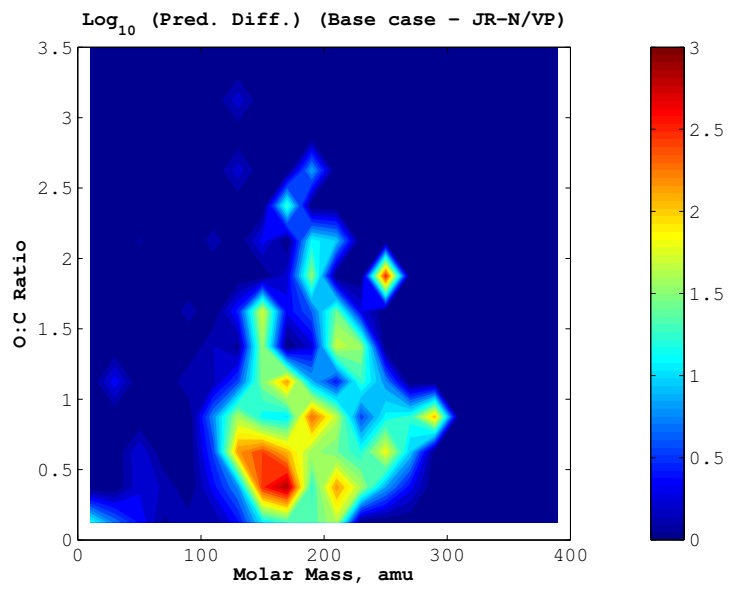

Fig. 6. The plot showing the factor difference in predicted binned organic condensed moles using the vapour pressure models shown in Fig. 5. The $\mathrm{Z}$ axis is the base 10 logarithm of the factor(JRN/VP divided by N-N/VP) in the cumulative concentration of the condensed components (in molecules $\mathrm{cm}^{-3}$ ) with negative values given a value of zero on this scale.

values are at higher $\mathrm{O}: \mathrm{C}$ ratio ( 0.76 compared to 0.39 for the base case), and lower molar mass (214 vs. 270) than the equivalent values in the earlier paper. The calculated O:C ratio of 0.76 for the base case is substantially higher than the $\mathrm{O}: \mathrm{C}$ ratio reported in recent studies of atmospheric aerosol in heavily urbanised areas: generally below 0.5 in London (Allan et al., 2010), and 0.36 in the New York area (Sun et al., 2011); but similar to the value of up to 0.8 for aged aerosol measured in the outflow from Mexico city (DeCarlo et al., 2008).

For molar mass the median values of 214 (or 155 for the hydrolysed case) seen in Fig. 7 will be substantially below an average value measured for an atmospheric sample due to the formation of oligomers (Reinhardt et al., 2007; Reemtsma et al., 2006) which are not considered in our model.

\subsubsection{Average functionality}

The most abundant functional groups in the predicted SOA were alcohols, hydroperoxides and ketones. In a recent publication (Valorso et al., 2011) the authors found the same three functional groups dominating predicted SOA composition for a low $\mathrm{NO}_{\mathrm{x}}$ scenario; although hydroperoxides were more prevalent than alcohols. Figure 8 shows the sensitivity of the average number of functional groups per molecule for these top three functional groups to changes in vapour pressure values, the inclusion of non-ideality, and the effect of hydrolysing the acid anhydrides. In general the distribution of the number of functional groups is relatively insensitive to the vapour pressure method used. This is particularly true for the hydroperoxides and ketones; less true for alcohols. For alcohols the striking feature is that some cases give predicted

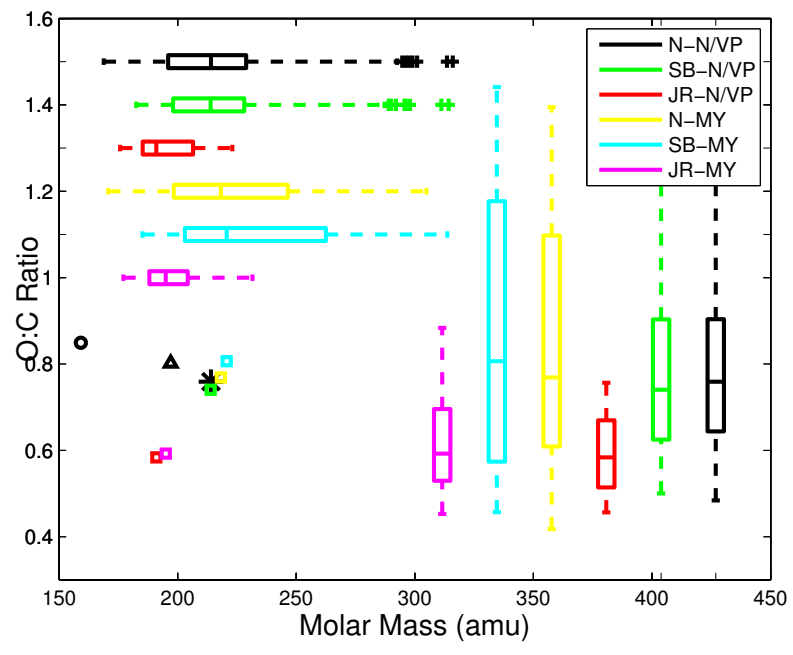

Fig. 7. The distribution of the average $\mathrm{O}: \mathrm{C}$ ratios and molar masses of the predicted condensed SOA across all cases for 27 scenarios with the box-and-whiskers showing the median, interquartile and $95 \%$ ranges for each combination of estimation techniques $\left(\gamma_{i}=1\right.$ assumed in all cases); the coloured squares (and the black asterisk) show the median values for the corresponding box-whisker plots. The other black symbols refer to variants of the base case (all $p^{0}$ by N-N/VP method):- black circle- hydrolysed case (2727 compounds, $\left.\gamma_{i}=1\right)$; black triangle- non-ideal case ( $\gamma_{i}$ by UNIFAC).

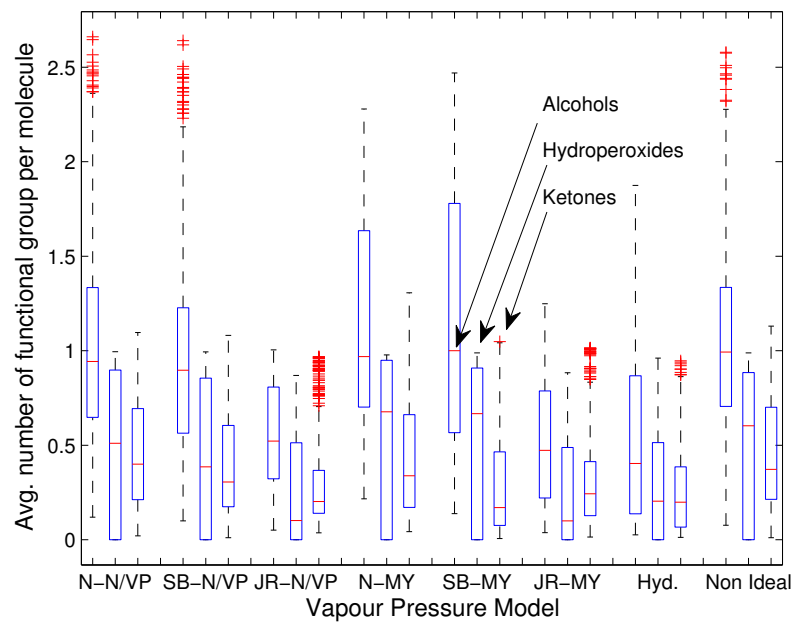

Fig. 8. Box-whisker plots showing the sensitivities of the average number of the three most abundant functional groups (alcohols, hydroperoxides and ketones) per molecule, across all cases for 27 scenarios using the partitioning model with (a) five vapour pressure estimation methods (plots 1-5, 2742 compounds, $\gamma_{i}=1$ ); (b) plot 6 shows the effect of hydrolysis of acid anhydrides (2727 MCM compounds, $p^{0}$ by N-N/VP, $\gamma_{i}=1$ ); (c) plot 7 shows the sensitivity to non-ideality (2742 compounds, $p^{0}$ by N-N/VP, $\gamma_{i}$ by UNIFAC).

SOA with an average of more than 2.5 alcohols per molecule. It is noticeable that the JR-N/VP and JR-MY methods (that predict much more SOA mass - see Fig. 2) do not show these extreme levels of alcohol participation suggesting that the 

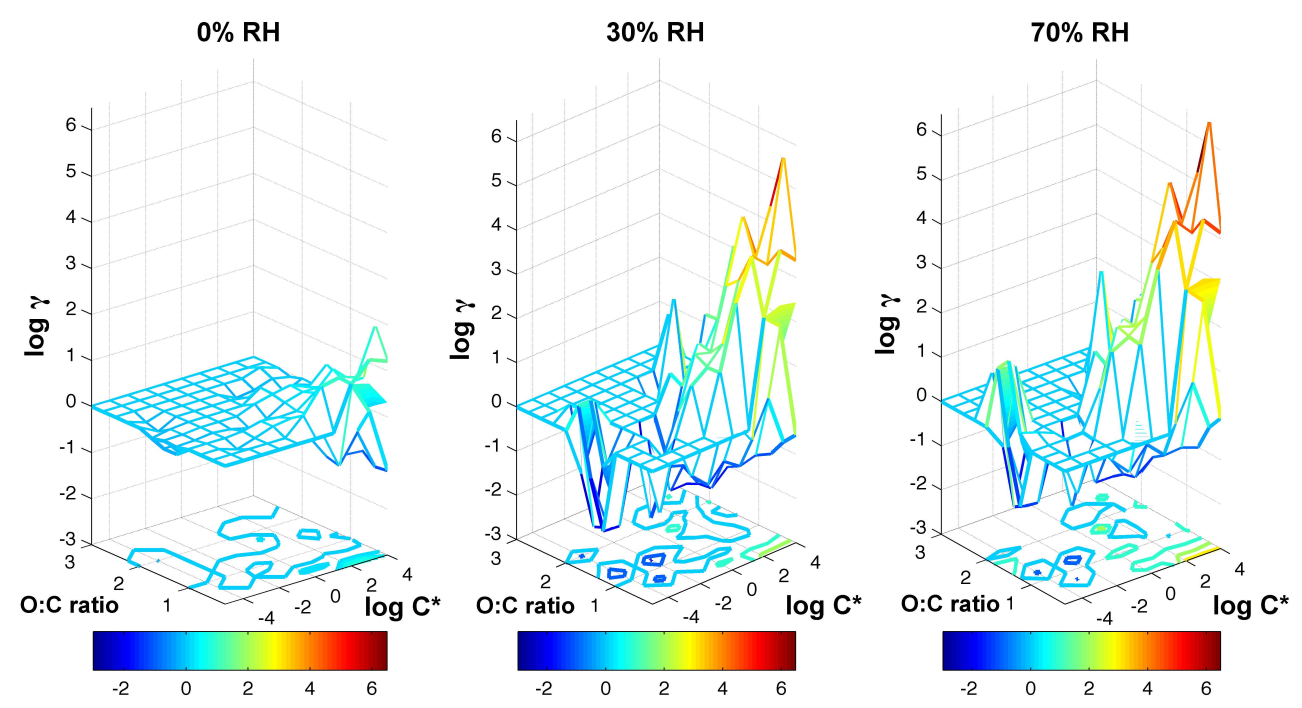

Fig. 9. Surface plots of $\log _{10}\left(\gamma_{i}\right)$ for the non-ideal calculation (2742 compounds, $p^{0}$ by N-N/VP, $\gamma_{i}$ by UNIFAC) using the standard scenario (1.0/1.0/1.0 NO $\mathrm{NO}_{\mathrm{x}}$-SF/AVOC-SF/BVOC-SF) under conditions $T=293.15 \mathrm{~K} ; \% \mathrm{RH}=0,30$ or 70 ; and $0.5 \mu \mathrm{g} \mathrm{m}^{-3}$ involatile core. The two meshes show the minimum and maximum activity coefficients as a function of $\mathrm{O}: \mathrm{C}$ ratio and $\log _{10}\left(C^{*}\right)$. The contour plot on the base of the figure shows the median value for each bin.

high alcohol levels may be associated with very low SOA mass. At very low SOA mass the polyalcohols are important contributors to SOA mass giving high $\mathrm{O}: \mathrm{C}$ ratios and high average molar mass. When more mass is condensed the polyalcohols become less important as components with lower molar mass and O:C ratio are included in the condensed material. This is consistent with the lower O:C ratios and lower median molar mass seen for the $p^{0}$ methods using $T_{\mathrm{b}}$ by JR in Fig. 7.

For the case including hydrolysis of anhydrides the average composition of SOA across 27 scenarios was significantly different to the base case with carboxylic acids displacing ketones to become the third most abundant functional group. This change is almost certainly due to the preponderance of maleic acid derivatives in the anthropogenically dominated scenarios after hydrolysis. This increase in carboxylic acid groups leads to a substantial reduction in the number of alcohols, hydroperoxides and ketones for the hydrolysed case (see Fig. 8). Note that the non-ideal case shows a very similar distribution for these top three functional groups to the base case.

The fourth and fifth most important functional groups in the predicted SOA are nitrate and nitro. The relatively high abundance of these groups is reflected in the high median $\mathrm{N}: \mathrm{C}$ ratio (0.1212), which is also significantly higher than the recently reported (Sun et al., 2011) value for urban aerosol (0.012).

\subsubsection{Variation in component non-ideality}

Figure 9 illustrates the variation in component non-ideality, for all the MCM components, for the standard scenario at 293.15 K and a range of RH values. This is represented by the variation in the logarithm of the predicted component activity coefficients with $\mathrm{O}: \mathrm{C}$ ratio and saturation concentration. It is clear that there is a wide variation in component activity coefficient, particularly at high $\% \mathrm{RH}$, ranging over several orders of magnitude (from $0.001-0.01$ for some components in the bin $\log C_{i}^{*}=-4$, up to $10^{5}$ for components in $\log C_{i}^{*}=+4$ ). The lowest activity coefficients are associated with the lowest volatility bins so these compounds (including the multifunctionalized cyclohexenes mentioned in Sect. 3.1) may dominate SOA composition at low SOA mass. In contrast the highest activity coefficients are associated with high volatility bins meaning that they are unlikely to contribute to SOA. These results demonstrate that the MCM compounds exhibit both salting in (activity coefficients below unity) and salting out (greater than unity) at all relative humidities. This is consistent with results reported by Compernolle et al. (2009) which show evidence for both salting in and salting out of SOA components with more salting out at high \% RH. It should be noted that, whilst it may be expected that components with high activity coefficients would tend to separate into one or more additional phases, those with low activity coefficients are very stable in the predicted mixture. It is therefore necessary to consider both positive and negative deviations from ideality to capture the effect of non-ideality on absorptive partitioning. In Donahue et al. (2011) the authors develop a two-dimensional 
volatility basis set model which allows the prediction of $\gamma_{i}$ from the volatility and O:C ratio of a component (see their Fig. 9). This model specifically aims to address salting out in POA/SOA mixtures and does not consider components to have $\gamma_{i}<1$. From Fig. 9 (and the component reordering exhibited in Fig. 3), it is clear that it is necessary to consider whether both positive and negative deviations from ideality will play a role in systems of interest in the atmosphere. The AIOMFAC model of Zuend et al. (2011) allows explicit consideration of phase separation in mixtures of inorganic and organic components and efforts are underway to explicitly include this consideration in the sensitivity studies. This will form the basis for subsequent publications.

\section{Conclusions}

Calculations of the absorptive partitioning of secondary organic aerosol components were carried out using a number of methods to estimate vapour pressure and non-ideality. The sensitivity of predicted condensed component masses, volatility, $\mathrm{O}: \mathrm{C}$ ratio, molar mass and functionality distribution to the choice of estimation methods was investigated in mixtures of around 2700 compounds generated by a near explicit mechanism of atmospheric VOC degradation. In a previous publication, the same sensitivity study was carried out for semi-randomly generated compounds, with the number of compounds ranging from 2 to 10000 . The two sets of compounds used in that study and in this report do have significant features in common. The condensed material from both sets are dominated by multifunctional compounds with a high proportion of oxygenated functionality which tend to give low or very low vapour pressures. The MCM compounds show a greater diversity of the carbon skeleton supporting the functional groups, although the effect of this should be minimal as the calculations of $p^{0}$ and $\gamma_{i}$ are largely driven by the functional groups .

In summary the results presented here agree with the main conclusion of McFiggans et al. (2010); namely that the variability from the base case attributable to non-ideality is not so large as the variability attributable to the selection of a vapour pressure model. This work demonstrates this for condensed SOA mass, volatility distribution, functional group distribution for the top three functional groups, O:C ratio and molar mass. Properties such as O:C ratio, average molar mass and average number of functional groups per molecule show much less sensitivity to physical property inputs than SOA mass. In addition the trends in key physical properties of condensed SOA over a wide range of emission scenarios have been explored at low BVOC, low AVOC and AVOC$\mathrm{SF}=\mathrm{BVOC}-\mathrm{SF}$. The trends suggest that the dependence of the properties on the $\mathrm{VOC}$ and $\mathrm{NO}_{\mathrm{x}}$ emissions are independent of the AVOC-SF:BVOC-SF ratio. Finally an analysis of the non-ideal behaviour of the MCM compounds over a range of relative humidities show a wide range of $\gamma_{i}$ val- ues including very low activity coefficients for low volatility components that may dominate SOA composition at low SOA mass. This demonstrates the importance of including the possibility of salting in $\left(\gamma_{i}<1\right)$ in SOA models considering non-ideality.

\section{Supplementary material related to this article is available online at: http://www.atmos-chem-phys.net/11/13145/2011/ acp-11-13145-2011-supplement.pdf.}

Acknowledgements. This work was carried out within the UK NERC-funded "QUantifying the Earth SysTem" (QUEST) project under the "QUest Aerosol and Atmospheric Chemistry" (QUAAC) grant number NE/C001613/1) and EU-funded "European Integrated project on Aerosol Cloud Climate and Air Quality interactions" (EUCAARI) under contract number 036833-2. DOT was supported by UK National Centre for Atmospheric Sciences (NCAS) funding. Additional support was provided by the NERC-funded "Vast Improvement" project NE/E018181/1, and grant NE/H002588/1 for the development of the informatics capability.

Edited by: V.-M. Kerminen

\section{References}

Allan, J. D., Williams, P. I., Morgan, W. T., Martin, C. L., Flynn, M. J., Lee, J., Nemitz, E., Phillips, G. J., Gallagher, M. W., and Coe, H.: Contributions from transport, solid fuel burning and cooking to primary organic aerosols in two UK cities, Atmos. Chem. Phys., 10, 647-668, doi:10.5194/acp-10-647-2010, 2010.

Aumont, B., Szopa, S., and Madronich, S.: Modelling the evolution of organic carbon during its gas-phase tropospheric oxidation: development of an explicit model based on a self generating approach, Atmos. Chem. Phys., 5, 2497-2517, doi:10.5194/acp-52497-2005, 2005.

Barley, M. H. and McFiggans, G.: The critical assessment of vapour pressure estimation methods for use in modelling the formation of atmospheric organic aerosol, Atmos. Chem. Phys., 10, 749767, doi:10.5194/acp-10-749-2010, 2010.

Barley, M., Topping, D. O., Jenkin, M. E., and McFiggans, G.: Sensitivities of the absorptive partitioning model of secondary organic aerosol formation to the inclusion of water, Atmos. Chem. Phys., 9, 2919-2932, doi:10.5194/acp-9-2919-2009, 2009.

Bilde, M., Svenningsson, B., Monster, J., and Rosenorn, T.: EvenOdd Alternation of Evaporation Rates and Vapor Pressures of C3-C9 Dicarboxylic Acid Aerosols, Environ. Sci. Technol., 37, 1371-1378, 2003.

Bloss, C., Wagner, V., Jenkin, M. E., Volkamer, R., Bloss, W. J., Lee, J. D., Heard, D. E., Wirtz, K., Martin-Reviejo, M., Rea, G., Wenger, J. C., and Pilling, M. J.: Development of a detailed chemical mechanism (MCMv3.1) for the atmospheric oxidation of aromatic hydrocarbons, Atmos. Chem. Phys., 5, 641-664, doi:10.5194/acp-5-641-2005, 2005.

Camredon, M. and Aumont, B.: Assessment of vapor pressure estimation methods for secondary organic aerosol modeling, Atmos. 
Environ., 40, 2105-2116, doi:10.1016/j.atmosenv.2005.11.051, 2006.

Camredon, M., Aumont, B., Lee-Taylor, J., and Madronich, S.: The SOA/VOC/NO $\mathrm{N}_{\mathrm{x}}$ system: an explicit model of secondary organic aerosol formation, Atmos. Chem. Phys., 7, 5599-5610, doi:10.5194/acp-7-5599-2007, 2007.

Capouet, M., Müller, J.-F., Ceulemans, K., Compernolle, S., Vereecken, L., and Peeters, J.: Modeling aerosol formation in alpha-pinene photo-oxidation experiments, J. Geophys. Res., 113, D02308, doi:10.1029/2007JD008995, 2008.

Chan, A. W. H., Chan, M. N., Surratt, J. D., Chhabra, P. S., Loza, C. L., Crounse, J. D., Yee, L. D., Flagan, R. C., Wennberg, P. O., and Seinfeld, J. H.: Role of aldehyde chemistry and $\mathrm{NO}_{\mathrm{x}}$ concentrations in secondary organic aerosol formation, Atmos. Chem. Phys., 10, 7169-7188, doi:10.5194/acp-10-7169-2010, 2010.

Compernolle, S., Ceulemans, K., and Müller, J.-F.: Influence of non-ideality on condensation to aerosol, Atmos. Chem. Phys., 9, 1325-1337, doi:10.5194/acp-9-1325-2009, 2009.

Compernolle, S., Ceulemans, K., and Müller, J.-F.: Technical Note: Vapor pressure estimation methods applied to secondary organic aerosol constituents from $\alpha$-pinene oxidation: an intercomparison study, Atmos. Chem. Phys., 10, 6271-6282, doi:10.5194/acp-10-6271-2010, 2010.

DeCarlo, P. F., Dunlea, E. J., Kimmel, J. R., Aiken, A. C., Sueper, D., Crounse, J., Wennberg, P. O., Emmons, L., Shinozuka, Y., Clarke, A., Zhou, J., Tomlinson, J., Collins, D. R., Knapp, D., Weinheimer, A. J., Montzka, D. D., Campos, T., and Jimenez, J. L.: Fast airborne aerosol size and chemistry measurements above Mexico City and Central Mexico during the MILAGRO campaign, Atmos. Chem. Phys., 8, 4027-4048, doi:10.5194/acp8-4027-2008, 2008.

Dommen, J., Metzger, A., Duplissy, J., Kalberer, M., Alfarra, M. R., Gascho, A., Weingartner, E., Prevot, A. S. H., Verheggen, B., and Baltensperger, U.: Laboratory observation of oligomers in the aerosol from isoprene/NOx photooxidation, Geophysical Research Letters, 33, L13805, doi:10.1029/2006GL026523, 2006.

Donahue, N. M., Epstein, S. A., Pandis, S. N., and Robinson, A. L.: A two-dimensional volatility basis set: 1. organic-aerosol mixing thermodynamics, Atmos. Chem. Phys., 11, 3303-3318, doi:10.5194/acp-11-3303-2011, 2011.

Fredenslund, A., Jones, R. L., and Prausnitz, J. M.: GroupContribution Estimation of Activity Coefficients in Nonideal Liquid Mixtures, AIChE Journal, 21, 1086-1099, 1975.

Gmehling, J.: Present status and potential of group contribution methods for process development, Journal of Chemical Thermodynamics, 41, 731-747, 〈GotoISI $\rangle: / / 000265466400003,2009$.

Gmehling, J., Onken, U., Arlt, W., Grenzhauser, P., Weidlich, U., Kolbe, B., and Rarey, J.: Vapor-Liquid Equilibrium Data Collection, Vol. 1, DECHEMA Chemistry Data Series, DECHEMA, Frankfurt am Main, Germany, http://www.dechema.de/en/CDS. html, 2002.

Goodwin, J. W. L., Salway, A. G., Murrells, T. P., Dore, C. J., Passant, N. R., King, K. R., Coleman, P. J., Hobson, M., Pye, S. T., and Watterson, J. D.: UK Emissions of air pollutants 19701999, AEAT/ENV/R/0798, National Atmospheric Emissions Inventory, 2001, Tech. rep., http://www.aeat.co.uk/netcen/airqual/ naei/annreport/annrep99/index.htm., 2001.

Hallquist, M., Wenger, J. C., Baltensperger, U., Rudich, Y., Simpson, D., Claeys, M., Dommen, J., Donahue, N. M., George,
C., Goldstein, A. H., Hamilton, J. F., Herrmann, H., Hoffmann, T., Iinuma, Y., Jang, M., Jenkin, M. E., Jimenez, J. L., Kiendler-Scharr, A., Maenhaut, W., McFiggans, G., Mentel, Th. F., Monod, A., Prévôt, A. S. H., Seinfeld, J. H., Surratt, J. D., Szmigielski, R., and Wildt, J.: The formation, properties and impact of secondary organic aerosol: current and emerging issues, Atmos. Chem. Phys., 9, 5155-5236, doi:10.5194/acp-95155-2009, 2009.

Hamilton, J. F., Lewis, A. C., Carey, T. J., and Wenger, J. C.: Characterization of polar compounds and oligomers in secondary organic aerosol using liquid chromatography coupled to mass spectrometry, Anal. Chem., 80, 474-480, 2008.

Hansen, H. K., Rasmussen, P., and Fredenslund, A.: Vapor-Liquid Equilibria by UNIFAC Group Contribution. 5. Revision and Extension, Industrial and Engineering Chemistry Research, 30, 2355-2358, 1991.

Heald, C. L., Jacob, D. J., Park, R. J., Russell, L. M., Huebert, B. J., Seinfeld, J. H., Liao, H., and Weber, R. J.: A large organic aerosol source in the free troposphere missing from current models, Geophys. Res. Lett., 32, L18809, doi:10.1029/2005GL023831, 2005.

Hoyle, C. R., Boy, M., Donahue, N. M., Fry, J. L., Glasius, M., Guenther, A., Hallar, A. G., Huff Hartz, K., Petters, M. D., Petäjä, T., Rosenoern, T., and Sullivan, A. P.: A review of the anthropogenic influence on biogenic secondary organic aerosol, Atmos. Chem. Phys., 11, 321-343, doi:10.5194/acp-11-321-2011, 2011.

Jenkin, M. E., Saunders, S. M., and Pilling, M. J.: The tropospheric degradation of volatile organic compounds: A protocol for mechanism development, Atmos. Environ., 31, 81-104, 1997.

Jenkin, M. E., Murrells, T. P., and Passant, N. R.: The Temporal Dependence of Ozone Precursor Emissions: Estimation and Application, AEAT/R/ENV/0355, AEA Technology, Harwell, 2000, Tech. rep., 2000.

Jenkin, M. E., Saunders, S. M., Wagner, V., and Pilling, M. J.: Protocol for the development of the Master Chemical Mechanism, MCM v3 (Part B): tropospheric degradation of aromatic volatile organic compounds, Atmos. Chem. Phys., 3, 181-193, doi:10.5194/acp-3-181-2003, 2003.

Joback, K. and Reid, R.: Estimation of Pure-Component Properties From Group-Contributions, Chemical Engineering Communications, 57, 233-243, doi:10.1080/00986448708960487, 1987.

Johnson, D., Utembe, S. R., Jenkin, M. E., Derwent, R. G., Hayman, G. D., Alfarra, M. R., Coe, H., and McFiggans, G.: Simulating regional scale secondary organic aerosol formation during the TORCH 2003 campaign in the southern UK, Atmos. Chem. Phys., 6, 403-418, doi:10.5194/acp-6-403-2006, 2006.

Kroll, J. H. and Seinfeld, J. H.: Chemistry of secondary organic aerosol: Formation and evolution of low-volatility organics in the atmosphere, Atmos. Environ., 42, 3593-3624, doi:10.1016/j.atmosenv.2008.01.003, 2008.

Kroll, J. H., Ng, N. L., Murphy, S. M., Flagan, R. C., and Seinfeld, J. H.: Secondary organic aerosol formation from isoprene photooxidation, Environ. Sci. Technol., 40, 1869-77, http: //www.ncbi.nlm.nih.gov/pubmed/16570610, 2006.

McFiggans, G., Topping, D. O., and Barley, M. H.: The sensitivity of secondary organic aerosol component partitioning to the predictions of component properties - Part 1: A systematic evaluation of some available estimation techniques, Atmos. Chem. 
Phys., 10, 10255-10272, doi:10.5194/acp-10-10255-2010, 2010.

Myrdal, P. B. and Yalkowsky, S. H.: Estimating pure component vapor pressures of complex organic molecules, Industrial and Engineering Chemistry Research, 36, 2494-2499, 1997.

Nannoolal, Y., Rarey, J., Ramjugernath, D., and Cordes, W.: Estimation of pure component properties Part 1. Estimation of the normal boiling point of non-electrolyte organic compounds via group contributions and group interactions, Fluid Phase Equilibria, 226, 45-63, 2004.

Nannoolal, Y., Rarey, J., and Ramjugernath, D.: Estimation of pure component properties. Part 3. Estimation of the vapor pressure of non-electrolyte organic compounds via group contributions and group interactions, Fluid Phase Equilibria, 269, 117-133, 2008.

Pandis, S. N., Paulson, S. E., Seinfeld, J. H., and Flagan, R. C.: Aerosol Formation in the Photooxidation of Isoprene and BetaPinene, Atmos. Environ., 25, 997-1008, 1991.

Pankow, J. F.: An Absorption Model of Gas-Particle Partitioning of Organic Compounds in the Atmosphere, Atmos. Environ., 28, 185-188, 1994.

Peng, C., Chan, M. N., and Chan, C. K.: The Hygroscopic Properties of Dicarboxylic and Multifunctional Acids: Measurements and UNIFAC Predictions, Environ. Sci. Technol., 35, 44954501, doi:10.1021/es0107531, 2001.

Reemtsma, T., These, A., Venkatachari, P., Xia, X. Y., Hopke, P. K., Springer, A., and Linscheid, M.: Identification of fulvic acids and sulfated and nitrated analogues in atmospheric aerosol by electrospray ionization Fourier transform ion cyclotron resonance mass spectrometry, Anal. Chem., 78, 8299-8304, 2006.

Reinhardt, A., Emmenegger, C., Gerrits, B., Panse, C., Dommen, J., Baltensperger, U., Zenobi, R., and Kalberer, M.: Ultrahigh Mass Resolution and Accurate Mass Measurements as a Tool To Characterize Oligomers in Secondary Organic Aerosols, Anal. Chem., 79, 4074-4082, doi:10.1029/2005GL023831, 2007.

Robinson, A. L., Donahue, N. M., Shrivastava, M. K., Weitkamp, E. A., Sage, A. M., Grieshop, A. P., Lane, T. E., Pierce, J. R., and Pandis, S. N.: Rethinking Organic Aerosols: Semivolatile Emissions and Photochemical aging, Science, 315, 1259-1262, doi:10.1126/science.1133061, 2007.

Saunders, S. M., Jenkin, M. E., Derwent, R. G., and Pilling, M. J.: Protocol for the development of the Master Chemical Mechanism, MCM v3 (Part A): tropospheric degradation of nonaromatic volatile organic compounds, Atmos. Chem. Phys., 3, 161-180, doi:10.5194/acp-3-161-2003, 2003.
Stein, S. E. and Brown, R. L.: Estimation of Normal Boiling Points from Group Contributions, Journal of Chemical Information and Computational Science, 34, 581-587, 1994.

Sun, Y.-L., Zhang, Q., Schwab, J. J., Demerjian, K. L., Chen, W.N., Bae, M.-S., Hung, H.-M., Hogrefe, O., Frank, B., Rattigan, O. V., and Lin, Y.-C.: Characterization of the sources and processes of organic and inorganic aerosols in New York city with a high-resolution time-of-flight aerosol mass apectrometer, Atmos. Chem. Phys., 11, 1581-1602, doi:10.5194/acp-11-15812011, 2011.

Topping, D. O., Barley, M. H., and McFiggans, G.: The sensitivity of Secondary Organic Aerosol component partitioning to the predictions of component properties - Part 2: Determination of particle hygroscopicity and its dependence on "apparent" volatility, Atmos. Chem. Phys., 11, 7767-7779, doi:10.5194/acp-11-77672011, 2011.

Valorso, R., Aumont, B., Camredon, M., Raventos-Duran, T., Mouchel-Vallon, C., Ng, N. L., Seinfeld, J. H., Lee-Taylor, J., and Madronich, S.: Explicit modelling of SOA formation from $\alpha$-pinene photooxidation: sensitivity to vapour pressure estimation, Atmos. Chem. Phys., 11, 6895-6910, doi:10.5194/acp-116895-2011, 2011.

Vivanco, M. G., Santiago, M., Martínez-Tarifa, A., Borrás, E., Ródenas, M., García-Diego, C., and Sánchez, M.: SOA formation in a photoreactor from a mixture of organic gases and $\mathrm{HONO}$ for different experimental conditions, Atmos. Environ., 45, 708715, doi:10.1016/j.atmosenv.2010.09.059, 2011.

Zuend, A., Marcolli, C., Booth, A. M., Lienhard, D. M., Soonsin, V., Krieger, U. K., Topping, D. O., McFiggans, G., Peter, T., and Seinfeld, J. H.: New and extended parameterization of the thermodynamic model AIOMFAC: calculation of activity coefficients for organic-inorganic mixtures containing carboxyl, hydroxyl, carbonyl, ether, ester, alkenyl, alkyl, and aromatic functional groups, Atmos. Chem. Phys., 11, 9155-9206, doi:10.5194/acp-11-9155-2011, 2011. 